\title{
The spectrum of blunt abdominal trauma in Pietermaritzburg
}

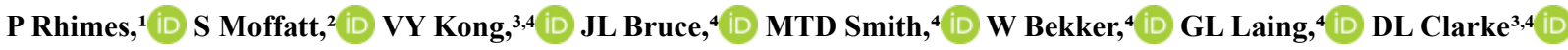 \\ ${ }^{1}$ Critical Care Directorate, Nottingham University Hospitals, United Kingdom \\ ${ }^{2}$ Emergency Department, University Hospital Coventry, United Kingdom \\ ${ }^{3}$ Department of Surgery, University of the Witwatersrand, South Africa \\ ${ }^{4}$ Department of Surgery, University of KwaZulu-Natal, South Africa
}

Corresponding author, email: victorywkong@yahoo.com

Background: This study reviews the Pietermaritzburg Metropolitan Trauma Service (PMTS) experience with the management of blunt abdominal trauma (BAT).

Methods: A retrospective review of the hybrid electronic medical registry (HEMR) between December 2012 and September 2019 was conducted. All patients admitted following BAT were included.

Results: During the study period, 1123 BAT patients were managed by the PMTS. The mean age was 29.19 years (SD 14.03). Of these admissions, $73.6 \%$ were male. The most common mechanism was road traffic crashes (RTCs) -435 motor vehicle collisions (MVCs) and 250 pedestrian vehicle collisions (PVCs). There were 186 assaults, 118 falls, 62 community assaults, 22 accidents related to agriculture, construction or industry, 11 sporting injuries, nine animal injuries, seven patients injured by falling objects, five injured by trains, two hangings, one burn-related fall and two other causes. The mechanism of injury was unknown in 22 cases. There were 445 abdominal CT scans and 270 whole body CT scans. Surgical management was required for 395 patients. There were 259 index laparotomies and 176 repeat laparotomies. Four patients underwent selective arterial embolisation. Laparoscopy was undertaken in ten, and subsequently converted to laparotomy in five. There were 106 orthopaedic operations. Hospital stay ranged from 0-155 days (median stay three days). ICU admission was required in $24.9 \%$ of patients. The mortality rate was $7.5 \%$.

Conclusion: BAT is common in South Africa. Whilst the vast majority of patients require non-operative treatment, a welldefined subset require a laparotomy. Imaging is central to the management of patients with BAT.

Keywords: blunt abdominal trauma, hybrid electronic medical registry

\section{Introduction}

Internationally, trauma is a leading cause of death in those less than 45 years old. ${ }^{1}$ In South Africa, despite a quarter of a century of relative political stability, trauma remains a major problem that places a huge burden on an already overstretched healthcare system. ${ }^{2}$ What makes the high burden of trauma in South Africa even more egregious is the high level of interpersonal violence which includes both blunt assault and frequently the use of firearms or bladed weapons. ${ }^{3}$ Much of the trauma oeuvre from South Africa over the last half-century has focused on penetrating trauma. ${ }^{4-9}$ However, a significant amount of trauma in South Africa is caused by blunt mechanisms. Common mechanisms for blunt trauma are road traffic injuries and non-penetrating violence.$^{10}$ Road traffic injuries are a major cause of death in South Africa with the mortality rate being 2.7 times that of the global mean. ${ }^{11}$ Assaults with fists, and blunt weapons are also common. Blunt abdominal injury can be particularly challenging for a number of reasons. The abdomen contains a large number of viscera and multiple organ injury is common. ${ }^{10}$ The mechanisms of injury in blunt abdominal trauma (BAT) often result in concurrent non-abdominal injury which may also need urgent intervention. Clinical examination is not diagnostically reliable ${ }^{12}$ and the use of
US scanning ${ }^{13}$ and CT scanning ${ }^{14}$ are important diagnostic tools. This study reviews the Pietermaritzburg Metropolitan Trauma Service (PMTS) experience of suspected BAT and describes the spectrum and investigation, management of BAT in our setting.

\section{Clinical settings}

The hybrid electronic medical registry (HEMR) is a registry of patients admitted to the PMTS. The PMTS provides definitive trauma care to Pietermaritzburg, the capital of KwaZulu-Natal province, and is a trauma centre which acts as a referral centre for 19 rural hospitals. The ethical approval to maintain the HEMR is granted by the University of KwaZulu-Natal's Biomedical Research Ethics Committee (BE221/13 and BE207/09).

\section{The study}

A retrospective review of the HEMR between December 2012 and September 2019 was conducted. All patients with suspected BAT on admission were included. Only patients treated at Grey's Hospital, Pietermaritzburg, were included in this study, patients who were transferred from Edendale Hospital for CT scanning were excluded. Patient characteristics were reported alongside mechanism of injury, 
imaging requirements, management (including surgical intervention) and mortality.

\section{Patient characteristics}

During the study period, 1123 patients were admitted with suspected BAT and were managed by the PMTS. The mean age of these patients was 29.19 years (SD 14.03). Of these admissions $73.6 \%(n=827)$ were male, $24.8 \%(n=279)$ were female and in $1.5 \%(n=17)$ of cases, the sex was not clear from the HEMR. The median ISS was 14. Patient characteristics are displayed in Table I and presenting physiology is displayed in Table II.

\begin{tabular}{lc} 
Table I: Patient characteristics & \\
\hline Total ( $\boldsymbol{n}$ ) & $\mathbf{1 1 2 3}$ \\
\hline Mean age (years) & 29.19 \\
Range of age (years) & $0.5-85$ \\
Median age (years) & 28 \\
Sex & Male 827, Female 279, \\
& unknown 17 \\
Injury to hospital mean time & 1 day 13 hours 27 minutes \\
Injury to hospital range & 27 minutes -118 days 1 hour \\
& 21 minutes \\
Injury to hospital median time & 14 hours 13 minutes \\
Injury to hospital SD & 6 days 7 hours 55 minutes
\end{tabular}

\section{Table II: Presenting physiology}

\begin{tabular}{|c|c|}
\hline Mean HR (BPM) & 98.65 \\
\hline HR range (BPM) & $18-197$ \\
\hline Median HR (BPM) & 96 \\
\hline Mean SBP (mmHg) & 121.22 \\
\hline SBP range (mmHg) & $47-237$ \\
\hline Median SBP (mmHg) & 120 \\
\hline Mean lactate $(\mathrm{mmol} / \mathrm{L})$ & 2.77 \\
\hline Lactate range $(\mathrm{mmol} / \mathrm{L})$ & $0.3-17$ \\
\hline Median lactate $(\mathrm{mmol} / \mathrm{L})$ & 1.8 \\
\hline Mean $\mathrm{pH}$ & 7.37 \\
\hline $\mathrm{pH}$ range & $6.87-7.63$ \\
\hline Median $\mathrm{pH}$ & 7.39 \\
\hline Mean BE (mmol/L) & -2.62 \\
\hline $\mathrm{BE}$ range $(\mathrm{mmol} / \mathrm{L})$ & $-27.6-15.8$ \\
\hline Median BE (mmol/L) & -2 \\
\hline Mean $\mathrm{HCO}_{3}^{-}(\mathrm{mmol} / \mathrm{L})$ & 22.33 \\
\hline $\mathrm{HCO}_{3}{ }^{-}$range $(\mathrm{mmol} / \mathrm{L})$ & $5.3-40.9$ \\
\hline Median $\mathrm{HCO}_{3}^{-}(\mathrm{mmol} / \mathrm{L})$ & 22.8 \\
\hline Mean $\mathrm{Hb}(\mathrm{g} / \mathrm{dL})$ & 11.62 \\
\hline $\mathrm{Hb}$ range $(\mathrm{g} / \mathrm{dL})$ & $4.1-22.8$ \\
\hline Median Hb (g/dL) & 11.65 \\
\hline
\end{tabular}

\section{Mechanism of injury}

The most common mechanism was road traffic crashes (RTCs) which accounted for $61 \%(n=685)$ of all cases. Of these, 435 were motor vehicle collisions (MVCs) and 250 were pedestrian vehicle collision (PVCs). There were 186 assaults, 118 falls, 62 community assaults, 22 accidents related to agriculture, construction or industry, 11 sporting injuries, nine animal injuries, seven patients injured by falling objects, five injured by trains, two hangings, one burn-related fall and two other causes. The mechanism of injury was unknown in 22 cases.

\section{Imaging}

There were 445 abdominal CT scans and 270 whole body CT scans. Imaging is summarised in Table III.

\begin{tabular}{lc} 
Table III: Imaging performed & \\
\hline CXR & 576 \\
AXR & 223 \\
CT abdomen & 445 \\
Whole body CT & 270 \\
CT thorax & 144 \\
CT pelvis & 174 \\
CT angio & 49 \\
Contrast meal/swallow & 9 \\
Cystogram & 79 \\
US abdomen & 49 \\
US pelvis & 3 \\
US thorax & 1 \\
FAST scan & 7
\end{tabular}

\section{Management}

The majority of patients $(64.8 \%)$ did not need surgical intervention. The remaining 395 patients required some form of surgical intervention, including orthopaedic surgery $(n=106)$ and other non-abdominal surgery $(n=129)$. There were 259 index laparotomies, of which $50.2 \%$ were conducted without prior abdominal CT. There were a total of 176 repeat laparotomies with several patients undergoing multiple repeat laparotomies. At index laparotomy, sple-

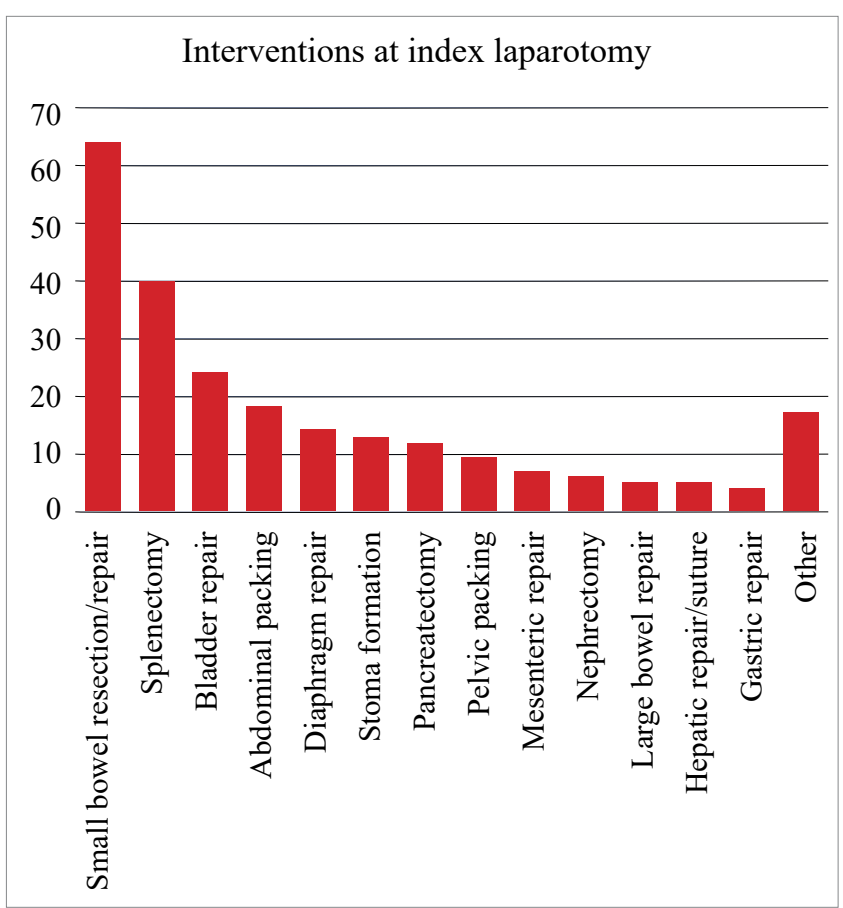

Figure 1: Interventions at index laparotomy 


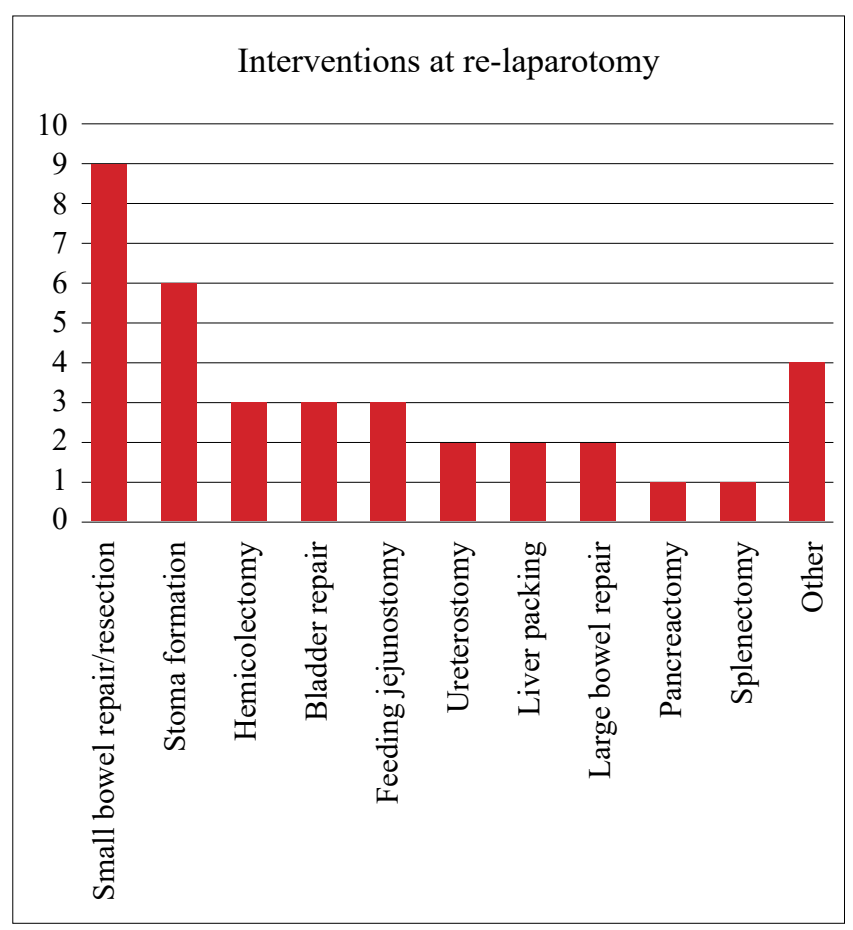

Figure 2: Interventions at re-laparotomy

nectomy, small bowel repair, bladder repair and hepatic packing were the most common interventions. Common interventions at laparotomy or repeat laparotomy are shown in Figure 1 and Figure 2. Two patients underwent selective embolisation for splenic injury, one for hepatic injury and one for a renal injury. Laparoscopy was undertaken in ten cases, and subsequently converted to laparotomy in five cases. Hospital stay ranged from 0-155 days with the median stay being three days. ICU admission was required in $24.9 \%$ $(n=280)$ of patients. The mortality rate was $7.5 \%(n=84)$.

\section{Discussion}

Our series demonstrates two main mechanisms of BAT in our region. The first is related to RTC and the second to interpersonal violence in the form of assaults by individuals and mobs. These two mechanisms accounted for $83 \%$ of the injuries described in this study. A coordinated nationwide multi-faceted strategy to reduce the high rate of road traffic related trauma is long overdue. Such a strategy will require political will and general buy-in from all stakeholders as it will require a major change in the culture of road usage. ${ }^{11}$ The experience with the total societal mobilisation around HIV/AIDS ${ }^{15}$ and more recently with the response to the COVID-19 pandemic ${ }^{16}$ suggests that it is possible to achieve the same with trauma in general and road traffic collisions in particular. Reducing the high rates of interpersonal trauma may be more difficult to achieve.

The management of BAT relies heavily on imaging. In the United Kingdom, it is rare for a case of BAT to proceed to surgery without first undergoing a CT scan. ${ }^{17}$ In our series, the rate is not as high. This difference is likely due to the disparity in injury severity and scanner availability between the two regions. It is difficult to rely on clinical examination to assess patients with injuries to multiple body regions. ${ }^{12}$ The use of sonar in the form of focused abdominal sonar for trauma (FAST) is increasingly common. ${ }^{18}$ We have still not fully developed this modality at our institution and there were only seven documented FAST scans in our series. CT remains the gold standard in assessing BAT; ${ }^{19}$ it is very sensitive in the detection of free fluid and it is able to diagnose solid organ injury and grade almost all solid organ injuries. FAST scan is increasingly used to identify the presence of intra-abdominal fluid. As such, FAST remains an excellent modality for ruling in abdominal injury but is poor in grading the severity of the injury and must usually be followed by a $\mathrm{CT}$ if a non-operative approach is to be followed. ${ }^{13}$

Hollow visceral disruption cannot be treated nonoperatively and the commonest indication for laparotomy was a small bowel injury. Blunt small bowel injury has been well described from our unit and is still associated with delay in recognition and morbidity. ${ }^{10,20}$ Duodenal injury and bladder disruption were also common indications for laparotomy. ${ }^{21}$ Solid visceral injuries, especially hepatic, splenic and renal are amenable to non-operative management (NOM) provided the patient remains in a state of haemodynamic stability. CT imaging helps grade these injuries and direct therapy. Selective embolisation, endo-urological intervention and laparoscopy are adjuncts which increase the scope of NOM in these injuries. ${ }^{22,23}$ The low number of embolisations in our series again reflects our institutions inability to deliver this intervention. Pancreatic trauma is insidious and associated with delayed recognition. Complete ductal disruption should mandate an operation. If the disruption is at the neck of the pancreas, distal pancreatectomy or pancreatico-gastrostomy are potential solutions. If the injury involves the pancreatic head and duodenum, then the initial operative approach is to control soiling and provide drainage. Once the patient is stabilised, these injuries usually require a formal pancreaticduodenectomy.

Surgical management is complex and there is a high rate of repeat operation. This is frequently secondary to the use of damage control procedures. Once the patient's physiology has been restored, definitive surgery can be undertaken, packs removed and open abdomens closed. Multiple, repeat laparotomies may be required to deal with ongoing intraabdominal sepsis. There is a high rate of non-abdominal operations in these patients and this reflects the fact that blunt torso trauma is truly polytrauma involving multiple body regions. The high rate of ICU admission and the high mortality rate reflect the severity of the polytrauma.

\section{Conclusion}

BAT is a common problem in South Africa. Whilst the vast majority of patients require non-operative treatment, a welldefined subset require a laparotomy. Imaging is central to the management of patients with BAT. Management is complex and associated with significant morbidity and mortality.

\section{Conflict of interest}

The authors declare no conflict of interest.

\section{Funding source}

None.

\section{Ethical approval}

The ethical approval to maintain the HEMR is granted by the University of KwaZulu-Natal's Biomedical Research Ethics Committee (BE221/13 and BE207/09). 


\section{ORCID}

P Rhimes (iD) https://orcid.org/0000-0002-9689-3688

S Moffatt (iD https://orcid.org/0000-0002-7649-4970

VY Kong (iD https://orcid.org/0000-0003-2291-2572

JL Bruce (iD) https://orcid.org/0000-0001-8666-4104

MTD Smith (iD https://orcid.org/0000-0002-6954-153X

W Bekker (iD https://orcid.org/0000-0003-0695-5994

GL Laing (iD) https://orcid.org/0000-0001-8075-0386

DL Clarke (iD) https://orcid.org/0000-0002-8467-1455

\section{REFERENCES}

1. Institute of Medicine (US) Committee on Injury Prevention and Control. Reducing the burden of injury: advancing prevention and treatment. Washington: National Academies Press; 1999. https://doi.org/10.17226/6321.

2. Lutge E, Moodley N, Tefera A, et al. A hospital based surveillance system to assess the burden of trauma in KwaZulu-Natal Province South Africa. Injury. 2016;47:13540. https://doi.org/10.1016/j.injury.2015.08.020.

3. Seedat M, Van Niekerk A, Jewkes R, et al. Violence and injuries in South Africa: prioritising an agenda for prevention. Lancet. 2009;374:1011-22. https://doi.org/10.1016/S01406736(09)60948.

4. Stein A, Schnier G. Penetrating stab wounds of the chest. S Afr Med J. 1965;39:548-53.

5. Khumalo-Mugabi L, Moffatt S, Bekker W, et al. Penetrating trauma in children and adolescents in Pietermaritzburg. South African J Surg. 2020;58:33-6. https://doi.org/10.17159/20785151/2020/V58N1A3017.

6. Koto MZ, Matsevych OY, Motilall SR. The role of laparoscopy in penetrating abdominal trauma: our initial experience. $\mathrm{J}$ Laparoendosc Adv Surg Tech. 2015;25:730-6. https://doi. org/10.1089/lap.2015.0042.

7. Demetriades D, Rabinowitz B, Sofianos C, et al. The management of penetrating injuries of the back. A prospective study of 230 patients. Ann Surg. 1988;207:72-4. https://doi. org/10.1097/00000658-198801000-00014.

8. Kong VY, Oosthuizen GV, Clarke DL. The spectrum of injuries resulting from posterior abdominal stab wounds: a South African experience. Ann R Coll Surg Engl. 2015;97:269-73. https://doi.org/10.1308/003588415X14181254789204.

9. Chamisa I. Civilian abdominal gunshot wounds in Durban, South Africa: a prospective study of 78 cases. Ann R Coll Surg Engl. 2008;90:581-6. https://doi. org/10.1308/003588408X301118.

10. Bekker W, Kong VY, Laing GL, et al. The spectrum and outcome of blunt trauma related enteric hollow visceral injury. Ann R Coll Surg Engl. 2018;100:290-4. https://doi. org/10.1308/rcsann.2018.0013.

11. Wesson HKH, Boikhutso N, Hyder AA, et al. Informing road traffic intervention choices in South Africa: the role of economic evaluations. Glob Health Action. 2016;9. https:// doi.org/10.3402/gha.v9.30728.
12. Jansen JO, Yule SR, Loudon MA. Investigation of blunt abdominal trauma. BMJ. 2008;336:938-42. https://doi. org/10.1136/bmj.39534.686192.80.

13. Stengel D, Leisterer J, Ferrada $P$, et al. Point-of-care ultrasonography for diagnosing thoracoabdominal injuries in patients with blunt trauma. Cochrane Database Syst Rev. 2018;12:CD012669. CD012669.pub2.

14. O'Neill SB, Hamid S, Nicolaou S, et al. Changes in approach to solid organ injury: what the radiologist needs to know. Can Assoc Radiol J. 2020;10:352-61. https://doi. org/10.1177/0846537120908069.

15. The Joint United Nations Programme on HIV/AIDS. New modelling research shows partial progress in South Africa's response to HIV; 2019. Available from: https://www. unaids.org/en/resources/presscentre/featurestories/2019/ june/20190628_south-africa-modelling. Accessed 1 Sep 2020.

16. Morris D, Rogers M, Kissmer N, et al. Impact of lockdown measures implemented during the Covid-19 pandemic on the burden of trauma presentations to a regional emergency department in Kwa-Zulu Natal, South Africa. African J Emerg Med. 2020 Dec;10(4):193-6. https://doi.org/10.1016/j. afjem.2020.06.005.

17. Pande R, Saratzis A, Winter Beatty J, et al. Contemporary characteristics of blunt abdominal trauma in a regional series from the UK. Ann R Coll Surg Engl. 2017;99:82-7. https:// doi.org/10.1308/rcsann.2016.0223.

18. Boulanger BR, Kearney PA, Brenneman FD, et al. Utilization of FAST (focused assessment with sonography for trauma) in 1999: Results of a survey of North American trauma centers. Am Surg. 2000;66:1049-55.

19. Bekker W, Smith MTD, Kong VY, et al. Isolated free fluid on computed tomography for blunt abdominal trauma - a South African experience. Ann R Coll Surg Engl. 2019;101:552-7. https://doi.org/10.1308/rcsann.2019.0078.

20. Bekker W, Hernandez MC, Zielinski MD, et al. Defining an intra-operative blunt mesenteric injury grading system and its use as a tool for surgical-decision making. Injury. 2019;50:2732. https://doi.org/10.1016/j.injury.2018.08.014.

21. Weale RD, Kong VY, Bekker W, et al. Primary repair of duodenal injuries: a retrospective cohort study from a major trauma centre in South Africa. Scand J Surg. 2019;108:280-4. https://doi.org/10.1177/1457496918822620.

22. Hildebrand DR, Ben-Sassi A, Ross NP, et al. Modern management of splenic trauma. BMJ. 2014;348:g1864-70. https://doi.org/10.1136/bmj.g1864.

23. Armstrong RA, Macallister A, Walton B, et al. Successful non-operative management of haemodynamically unstable traumatic splenic injuries: 4-year case series in a UK major trauma centre. Eur J Trauma Emerg Surg. 2019;45:933-8. https://doi.org/10.1007/s00068-018-0975-y. 